\title{
Comercio trasatlántico y comercio regional ganadero en América (1492-1542)
}

\author{
JUSTO L. DEL RIO MORENO
}

\section{UNA CUESTION CULTURAL}

En la historiografía americanista no es nueva la vinculación entre la reconquista del reino de Granada y la conquista de América, estableciéndose también determinadas similitudes entre los poblamientos canario y antillano. En esta relación de continuidad; las temáticas analizadas han sido muy dispares, yendo desde el estudio de las huestes y sus armas o técnicas de combate hasta la investigación del establecimiento de ciudades, su desarrollo o la paralela expansión económica.

Centrándonos en lo que fue el proceso de sometimiento de territorios ocupados por infieles -ya fueran nazaríes, güanches; o indios americanos-, se pueden presentar algunos elementos comunes que nos sirven para contextualizar los distintos procesos bélicos que emprendió Castilla a fines del siglo XV, advirtiéndose en primer lugar, que en todos ellos se tuvo presente el móvil religioso, enfocándose la guerra como una cruzada contra el infiel:

Como es natural, los conquistadores no se desplazaban exclusivamente por el espíritu de cruzada, subyaciendo en este esquema teórico de empresa religiosa un sustrato económico que movilizaba a los hombres -a soldados y financieros- y garantizaba la obtención de recursos para su pertrechamiento y transporte marítimo hasta el territorio objeto de ocupación, esquematizándose este móvil en el botín. Esta recompensa era necesaria para remunerar tanto a los soldados como a los empresarios que se hacían cargo de sufragar la iniciativa, por lo que frecuentemente su obtención era casi imperiosa, condicionando el propio desarrollo del proceso bélico.

Por último, tras el sometimiento de los vencidos y el establecimiento de poblaciones en los nuevos territorios, se producía un tercer fenómeno, que caracteriza a los nuevos descubrimientos geográficos: surgía una fuerte corriente migratoria que seguía los pasos de los primeros soldados.

Guerreros, misioneros y colonos se desplazaban desde Castilla al Nuevo Mundo llevando consigo el acervo cultural de su tiempo, implicando este traslado humano para las posteriores generaciones "criollas" -entendiendo el término con la acepción empleada por los americanistas en la Historia Social- la recepción de una cultura en la que imperaban unas pautas económicas y sociales muy vinculadas al mundo ganadero, con una dualidad de formas, medievales y renacentistas, en las que se entremezclaban los usos comunales de aprovechamiento del suelo con las explotaciones privadas.

DOI: http://dx.doi.org/10.25267/Trocadero.1995.i6.13 
La cultura ganadera castellana, con sus vertientes material e inmaterial, llegó a América al compás de los hombres, de forma consciente e inconsciente, de diversas maneras y en distintas corrientes. En esta ocasión, dada la amplitud de la temática expuesta, nos limitaremos exclusivamente a presentar algunas perspectivas del traspaso de las formas tangibles de dicha cultura; en concreto, nos referiremos al comercio de ganados, primero interoceánico -entre Andalucía y América- y después regional, prestando especial atención al área circuncaribeña y dentro de ella al caso dominicano.

A fines del siglo XV España era un país eminentemente pecuario, si bien había ya por entonces múltiples diferencias entre sus distintas regiones en lo que a ganadería se refiere. Así, mientras que en el centro de Castilla predominaba la cría ovina, algunas comarcas del sur de Extremadura y de la Andalucía Bética comenzaban a especializarse en la explotación del vacuno y del porcino. De esta manera, frente a una ganadería transhumante que se fundamentaba en los grandes contrastes geográficos y climáticos, que exigían el cambio semestral de los rebaños en busca de hierbas, surgieron ganaderias "estantes", que pacían perennemente en terrenos acotados o adehesados, cuyo pasto no era comunal.

En este tiempo, la Mesta comenzaba a ganar protagonismo y en la mayor parte del país, ya fuera con uno u otro tipo de explotaciones, la ganadería progresaba más rápidamente que la agricultura; tal vez, porque la producción de carne, lana y cueros tenía una protección más fácil o, quizás, porque era más rentable que el cultivo de cereales, olivares y viñedos.

Este crecimiento pecuario - de ganados mesteños y estantes- no sólo se debía al apoyo regio, que veía incrementadas sus rentas con las exportaciones de lana, sino también a las circunstancias económicas y sociales que vivía por entonces Castilla, donde los precios de los granos estaban tasados, las cosechas eran más inseguras -por circunstancias climáticas o bélicas-, requerían más mano de obra y donde las tierras dedicadas a cultivo estaban limitadas -las siembra sólo era factible en el ruedo y en terrenos vallados o amojonados-, mientras que las inmesas tierras baldías o concejiles destinadas a pasto eran de aprovechamiento comunal y permitían la ampliación del negocio pastoril.

Como una parte más de su cultura, los conquistadores establecieron en América esta dualidad ganadera a la que nos hemos referido, prefiriendo también los negocios pecuarios antes que los agrícolas, que en un primer momento quedaron en manos de la población aborigen, si exceptuamos aquellos cultivos cuya producción se destinaba al mercado europeo y requerían una mayor tecnificación productiva.

En el Nuevo Mundo, pese a que durante las primeras décadas de colonización prevaleció la comunidad de pastos, pronto surgieron dos formas distintas de ganaderías: ovina y de explotación comunal -vinculada a la derrota de mieses y a la existencia de amplios espacios baldios-, con un primer desarrollo en el suroeste de La Española (en las tierras situadas entre Azua y San Juan de la Maguana) y una posterior expansión por el centro y norte de Nueva España, una vez garantizados los privilegios pastoriles por el cabildo de México con la creación de una mesta novohispana e institucionalizada la organización por el virrey Velasco II, tras la promulgación de las Ordenanzas de Agostadero.

Paralelamente, frente a este tipo de ganaderías, aparecían otras formas de aprovechamiento pecuario en los hatos, con extensiones de una legua cuadrada o 
rendonda de pastos que, si bien en un primer momento fueron comunales, no tardaron en privatizarse mediante distintos mecanismos.

La atracción que sentían los españoles por los negocios ganaderos estaba condicionada por múltiples factores, tanto de carácter externo como interno. Entre los primeros destacaban aquellos puramente culturales, que conectaban a los hombres con las tradiciones pecuarias castellanas o con las prácticas sociales peninsulares, pues los conquistadores consideraban denigrante, indigno o impropio de su nueva posición social el trabajo manual en la tierra. Por otra parte, en este contexto tan negativo para la agricultura tradicional del Viejo Mundo, las costumbres económicas y nutritivas existentes en las distintas regiones del centro y sur de España conectaban más al soldado con el ganado que con los cultivos.

Entre los factores de origen interno, hemos de considerar que, desde los primeros años de la colonización, la carne empezó a privalecer en la alimentación sobre el cereal o el pan de yuca en su ausencia, aportando la mayor parte de las calorías. Esta orientación nutritiva se debía a varias razones, entre otras, a que las tierras eran abundantes y la ganadería exigía menos mano de obra -que así podía destinarse a las extracciones auríferas-; a que, por otra parte, la población aborigen se encontraba atrasada técnicamente, desconocía los cultivos europeos y era necesario invertir tiempo y recursos económicos en aculturarla; al mayor número de calorías obtenidas de tocinos y perniles en comparación con verduras y granos y, por último, a la imposibilidad de obtener cosechas de trigo, vino o aceite en los territorios tropicales que se poblaban, con la consecuente dependencia del abasto andaluz.

\section{PROPIEDAD PUBLICA O PRIVADA}

A tenor de lo expuesto y de investigaciones más amplias que hemos llevado a cabo en los últimos años, parece más que evidente que la cultura ganadera vigente en la vida peninsular tuvo su continuación en América, reflejándose los vínculos que unían a hombres y ganados ya en las páginas de las primeras Crónicas del período de los grandes descubrimientos, tal y como testimonian las anotaciones que hacían en sus escritos Cristóbal Colón, Pedro Mártir de Anglería, Miguel de Cúneo, Andrés Bernáldez, Bartolomé de las Casas o Francisco López de Gómara, quienes no dejaron de presentar sus primeras impresiones sobre las perspectivas pecuarias que ofrecía el Nuevo Mundo (1).

Después del segundo viaje colombino, en el que únicamente se embarcaron un reducido número de cabezas porcinas y equinas, las siguientes flotas que fueron a América llevaron de Andalucía pequeñas partidas de ganado caballar y vacuno (2), adquiriéndose mayoritariamente el lanar y caprino en los puertos canarios (3).

(1) Gil, Juan y Varela, Consuelo: Cartas de particulares a Colón y Relaciones coetáneas. Madrid, Alianza Editorial, 1984, p. 49. Bernáldez, Andrés: Historia del reinado de los Reyes Católicos. Madrid, Tipografia Blass, 1962, cap. CXX, p. 301. Las Casas, Bartolomé de: Historia de las Indias. México, F.C.E., 1951, lib. I, cap. LXXXII, p. 346. López de Gómara, Francisco: Historia General de las Indias. Barcelona, Edit. Orbis, 1985, t. I, p. 55

(2) Archivo General de Indias (En adelante AGI), Contratación, 3.249, tibro 2 de Armadas, f. 22.

(3) AGI, Contratación, 3.249, lib. 2 de Armadas, f. 31. Pérez de Tudela Bueso, Juan: Las armadas de Indias y los orígenes de la política de colonización (1492-1505). Madrid, Instituto Fernández de Oviedo, 1956, p. 112. 
En conjunto, si contabilizamos las remesas trasladadas en estos primeros años, se advierte una notable preponderancia del ovino, preferencia que sin duda conecta con la política ganadera -en favor de la Mesta- que desarrollaban los Reyes Católicos en España y que, en virtud del inusitado interés que mostraron, evidencia su extensión hacia América, aplicándose una combinación de ideas económicas portuguesas -la instalación de factorias con un monopolio regio- y castellanas - el desarrollo de la cría ovina para atender las enormes expectativas que tenía el mercado lanero-. Con esta trasposición pecuaria, el objetivo de la Corona era doble, por una parte, crear sus propios rebaños al otro lado del Atlático y obtener nuevos dividendos para la Real Hacienda; por otra, encontrar una viabilidad económica a los nuevos territorios para sostener el poblamiento y garantizar la paralela ampliación de soberanía (4).

En estos primeros momentos de la colonización, los planes ganaderos estatales no dieron los frutos esperados y tras prolongados fracasos durante la última década del siglo XV, por inadaptación del ovino y caprino, los intentos tendentes a crear una importante ganadería en América se sucedieron nuevamente en los primeros momentos del siglo XVI, a través de capitulaciones de poblamiento como las de Luis de Arriaga y Vélez de Mendoza, así como en las propias instrucciones de gobierno dadas al nuevo gobernador, el extremeño frey Nicolás de Ovando.

En adelante, el rumbo económico que siguió La Española fue muy distinto al trazado inicialmente por los Reyes y Fonseca, mientras que la crianza se orientó no ya hacia el ovino, sino hacia el porcino, caballar y vacuno.

Durante todo el tiempo en que la Corona mantuvo sus privilegios económicos (1492-1504), el negocio ganadero estuvo sólo y exclusivamente en manos de los oficiales de la Real Hacienda. Tal vez por esta razón, si exceptuamos el caso porcino, la implantación pecuaria fue un absoluto fracaso.

La pretensión real de crear una importante producción pecuaria en La Española era acertada, además de conveniente, para alimentar a los nuevos pobladores europeos y crear una economía semejante a la castellana. Sin embargo, tales deseos no pudieron materializarse sin una iniciativa privada que los potenciara. A esta situación se llegó, probablemente, porque los colonos no iban mentalizados para asentar en la tierra y fomentar la crianza, sino para buscar oro y volver a España entiquecidos.

Por otra parte, los rebaños trasladados fueron númericamente escasos, contaron con pocos cuidados - al ser una propiedad estatal- y su adaptación al nuevo clima resultó tan problemática que, hasta bien entrada la primera década del siglo XVI, las necesidades nutritivas de la población demandante crecieron muy por encima de la producción de carne.

\section{LAS ETAPAS DEL COMERCIO ATLANTICO PECUARIO}

Los primeros intentos aperturistas a la propiedad privada del ganado los encontramos a principios de 1502, momento en el que comenzaron a otorgarse ciertas libertades a los hombres que se acogieron a las capitulaciones de poblamiento firmadas con Luis de Arriaga y Velez de Mendoza.

(4) AGI, Contratación, 3249, ff. 105 y $125 \mathrm{v}$. 
Estas iniciativas tuvieron escaso éxito, en lo que a implantación pecuaria se refiere, tal vez, por las limitaciones con que fue concebido el plan económico a desarrollar, tanto en el corto número de personas a que afectaba como en las reducidas posibilidades mercantiles que se les ofrecían. Así pues, ante la escasa motivación de los colonos, la alimentación cárnica de los nuevos pobladores siguió siendo sumamente precaria.

Atento a la evolución que seguía el abasto, Ovando debió informar de ello detalladamente y ofrecer algunas alternativas. Siguiendo su prudente parecer, al año siguiente, la Corona consintió el comercio pecuario entre Andalucía y América a todos los colonos que desearan intervenir en él, si bien mantuvo aún las principales prerrogativas del monopolio económico: que creara con su socio el Almirante, permaneciendo vedada la compra-venta de animales en La Española, actividad que sólo podían desempeñar los oficiales reales.

Pese al efecto positivo que inicialmente tuvo la medida anterior sobre la economía dominicana, pronto se comprendió, tanto en Santo Domingo como en España, que la prerrogativa era insuficiente, pues aún eran muy pocos los españoles que se aventuraban a invertir en ganadería, dadas las escasas ganancias que prometía la crianza sin la existencia de un libre mercado. La situación se complicó cuando comenzaron a explotarse los ricos yacimientos auríferos del Ozama y, a la fama del oro, llegaron más españoles, incrementándose los precios de los alimentos y otros productos básicos en porcentajes tan elevados que no hubo más solución que prohibir la inmigración para restringir la demanda.

Paralelamente, con la intención de aumentar la oferta de carnes y de los productos y herramientas de mayor consumo, Nicolás de Ovando sugirió a la Corona la legalización de todas las actividades comerciales, incidiendo expresamente en las pecuarias, consintiéndose que los colonos intervinieran en este negocio a mediados de 1504, momento a partir del cual apareció un comercio ganadero regular y homogéneo entre uno y otro lado del Atlántico, que permitió el progreso de la ganadería en América.

Tras un análisis pormenorizado de los puntos de destino de los distintos embarques, y los tipos de ganados exportados desde Andalucía y Canarias, hemos llegado a la conclusión de que en el período 1503-1550 existieron cuatro fases claramente diferenciadas.

Según el criterio anteriormente expuesto, la primera etapa comprende los años que transcurren entre 1503 y 1507 y se caracteriza por el predominio de las exportaciones de équidos, la mayor parte de ellos yeguas y asnos, dirigidos exclusivamente hacia los puertos de Santo Domingo y Puerto Plata, ambos en La Española. Estas importaciones tenían un destino diverso, según las necesidades y posición social de los distintos demandantes. Los pollinos eran adquiridos por arrieros y mineros, fundamentalmente, quienes los empleaban en el transporte terrestre de hombres, mercancías y metales. Por el contrario, caballos y yeguas, eran comprados por los encomenderos más ricos y por los miembros de la Administración, destinándose a la defensa militar, el transporte de personas y a distintos usos sociales como juegos, paseos, etc., prácticas propias de la clase nobiliaria que imitaban los nuevos ricos, donde exhibían el lujo tanto en los animales como en los jinetes.

El segundo período se desarrolla entre 1507 y 1510, dirigiéndose también la mayor parte de los cargamentos hacia los puertos ya citados de La Española, desta- 
cando en las exportaciones el vacuno, ovino y caprino. Estas importaciones se caracterizan por la intención que mueve a los demandantes, tendente a crear ganaderías que abastecieran y diversificaran la oferta de carne en el mercado, surgiendo primero como un complemento, y después de 1508 , como una alternativa económica a la minería, siendo adquiridos los animales por los encomenderos más prósperos y los miembros de la Administración que deseaban ya establecerse en la isla.

La tercera fase se extiende desde 1511 hasta 1520, y entre los ganados trasladados predominaban vacunos, équidos y sementales de distintas especies, destinados a Puerto Rico, Jamaica, Cuba y La Antigua del Darién. Cuantitativamente, este tráfico tiene ya menor importancia que en las dos etapas anteriores, si bien desde una perspectiva cualitativa su valor es mucho mayor, pues en general se trata de importaciones de ejemplares escogidos que tienden a mejorar la raza de las ganaderías ya existentes en América. De hecho, en este tercer período, tiene ya un mayor peso el tráfico regional, procedente de las distintas explotaciones establecidas en La Española, tanto si se analiza el número de cabezas de distintas especies con las que se opera como si se estudian los recursos que mueve este comercio.

Por último, la cuarta etapa perdura desde principios de la década de 1520 hasta finales del decenio de 1550, embarcándose en los puertos de Andalucía y Canarias pequeñas partidas de garañones equinos -asnos y caballos- y ovinos -algunos merinos dirigidos a Nueva España-, otro pequeño número de remesas caprinas destinadas a Nueva España, Guatemala, Tierra Firme y Perú y algunos cargamentos de mulas para los centros comerciales continentales de mayor demanda, en concreto para Nombre de Dios, Panamá y Lima.

Pese a la existencia de estas exportaciones desde el Viejo Continente, durante este cuarto periodo predomina ya claramente el intercambio regional, primero, entre los principales puertos antillanos (Santo Domingo, Azua, Salvatierra de la Sabana, La Yaguana y Puerto Plata en La Española; San Germán y San Juan en Puerto Rico; Sevilla la Nueva, Melilla y Oristán en Jamaica; así como Santiago y La Habana en Cuba) y la cuenca caribeña de Nueva España y Tierra Firme, y después, entre los puertos anteriormente citados y el Perú o el interior de Tierra Firme, partiendo de centros redistribuidores como Panamá, El Tocuyo y otros focos de asentamiento de la costa continental, en un proceso de irradiación que llegaba con la colonización y seguía las rutas establecidas por los propios conquistadores.

Sin ninguna duda, más por su importancia innovadora y de respuesta a unas necesidades inmediatas que por su valor numérico, dada la novedad de trasladar ganados en barcos por distancias tan largas y lo problemática que resultaba la adaptación y reproducción de los animales en el trópico, las fases más importantes del comercio atlántico de ganados fueron las dos primeras, motivo por el cual nos limitaremos en esta ocasión a analizar su desarrollo, sin olvidarnos por ello del análisis del comercio regional caribeño, intercambio que se complementaba y estaba directamente relacionado con el anterior.

\section{LOS TRATANTES DE GANADOS}

Entre los hombres que intervenían en estas actividades, al menos en el período comprendido entre 1503 y 1520 , pueden distinguirse cuatro tipos de comer- 
ciantes si nos fijamos en su lugar de residencia, oficios que desempeñaban o tipos de negocios que desarrollaban.

Un primer grupo estaba constituido por algunos vecinos de los principales puertos andaluces, en concreto de Sevilla, Cádiz, Huelva, Palos y Moguer. Estos hombres no eran mercaderes profesionales, sino pequeños empresarios -con suficientes ahorros-- que desempeñaban actividades muy dispares (tales como panaderos, sastres, boticarios, toneleros, etc.), que de una u otra manera se relacionaban con el comercio americano. Esta vinculación con América y las noticias que llegaban sobre las perspectivas de futuro del nuevo mercado, les permitía conocer más detalladamente cuáles eran las demandas dominicanas y, al mismo tiempo, les motivaba para invertir sus capitales en la satisfacción de tales pedidos (5).

Un segundo grupo lo constituían aquellas personas que trabajaban en la Carrera de Indias y estaban en contacto con importadores y exportadores. En concreto, nos estamos refiriendo a un reducido número de armadores, maestres, pilotos y en menor medida marineros, que conocían el mercado y las posibilidades lucrativas derivadas del tráfico (6).

El tercer tipo de tratante estaba integrado por los mercaderes de oficio, es decir por la gente que habitualmente intervenía en el comercio desarrollado entre Sevilla y los principales puertos del Mediterráneo y del Atlántico Norte. Sin ninguna duda, este era el grupo más importante y lo componían individuos procedentes de las agrupaciones: de genoveses, burgaleses y sevillanos. El papel que desempeñaron estos profesionales en el tráfico ganadero fue incrementándose con el paso de los años, a medida que iban instalándose los respectivos factores y comenzaba a surgir una red comercial.

Finalmente, también tomaron un gran interés por la práctica mercantil los propios isleños, atentos al ahorro de capital que les suponía la gestión personal de sus demandas y necesidades, e incluso, muy probablemente, como excelente inversión de los recursos que obtenían en las actividades mineras, comerciales o administrativas.

\section{LOS ACUERDOS COMERCIALES}

Conforme fue desarrollándose este comercio, las distintas personas o conjuntos de individuos que intervenían en él, bien fuese de forma especializada y continuada o esporádicamente, tendieron a establecer diversas asociaciones entre sí, pues de esta manera reducían los riesgos económicos de las operaciones y los físicos del viaje, disminuían los gastos del transporte y aumentaban los márgenes de beneficio.

La vinculación económica más utilizada por estos grupos fue la compañía, tal vez, por los cuantiosos recursos que debían invertirse o por la dificultad de realizar numerosas operaciones por parte de una sola persona sin emplear asalariados. El análisis de la documentación evidencia que este tipo de acuerdos se

(5) Sobre un total de 32 documentos de embarque recopilados, casi una tercera parte corresponden a personas que ostentaban profesiones de curtidor, candelero, ropero, trapero, bizcochero, etc.

(6) También aparecen oficios como marinero, maestre de nao y piloto. 
establecía entre individuos que conocian el negocio, sus perspectivas y riesgos, aunque también encontramos a auténticos inexpertos entre los isleños que retornaban o entre aquellos otros que emigraban por primera vez. Algunos contratos de sociedades muestran claramente este deseo de aunar esfuerzos, si bien se advierte la existencia de distintos grados de desarrollo del asociacionismo. Los mercaderes más experimentados sabían claramente -los más novicios en este tráfico, tal vez, intuían- que para rentabilizar el transporte pecuario debían operar con partidas importantes numéricamente, siendo mayor la inversión en aquellas sociedades de mercaderes profesionales, en especial de genoveses y burgaleses.

Pese a las enormes diferencias que había entre unas compañías y otras en cuanto al volumen total de sus transacciones, todas ellas tenían en común varios aspectos. Lo más normal es que su gestación se relacionara con la dificultad que tenía un individuo aislado para reunir fuertes sumas de capital, aunque también influían otros factores como la reducción de los gastos en la infraestructura comercial, con el reparto de funciones entre sus miembros, así como los riesgos (7).

Por lo general, en este tipo de acuerdos, uno de los socios se trasladaba con los animales, de esta forma los restantes compañeros conseguían el cuidado de tan delicado cargamento -durante la travesía y el período de adaptación al clima-, así como el buen resultado de la no menos conflictiva venta, ante la dificultad del cobro en efectivo y las importantes oscilaciones de los precios en Santo Domingo. Los compañeros que permanecían en Sevilla aseguraban una legítima y leal venta, incluyendo en el contrato de constitución de la sociedad una claúsula por la que se obligaba al desplazado a realizar la transacción ante ciertas personas que actuaban como testigos o a la realización del correspondiente documento de venta ante notario público, donde se hacía constar el precio y las condiciones de cobro.

La duración de las sociedades era muy variada, oscilando entre aquellas constituidas por toda una vida y las que se formaban por el tiempo que durara un único viaje - de ida y vuelta-, siendo lo más corriente que no sobrepasaran los cinco años (8).

Otro modelo de agrupación comercial fue el llamado de encomienda, la "commende" italiana, también llamada "societas maris" y "collegantia". Este tipo de acuerdo se establecía entre dos individuos, uno, que permanecía en el lugar de embarque, y otro, que se desplazaba con el ganado o vivía en América para recepcionar el cargamento. Comunmente, estos convenios suelen tener un doble sentido en la documentación: por un lado, aparecen como una actividad realizada para otro, previo acuerdo de las partes en los porcentajes de ganancia a percibir por el encomendero; por otro, constan también con una retribución específica del que aceptaba y ejecutaba el compromiso. En estos acuerdos lo más normal era que los ganados encomendados fuesen registrados a nombre de la persona que estaba encargada de su venta en América, la cual solía viajar en el navío para hacerse cargo de su correcto acomodo y alimentación.

(7) Martínez Gijón, José: La práctica del comercio por intermediario en el tráfico con las Indias durante el siglo XVI. Separata del Anuario de Historia del Derecho Español, Madrid, 1970.

(8) Archivo de Protocolos de Sevilla (En adelante APS), of. X, año 1508, lib. 1, f. 105. 
El tercer tipo de vínculo económico era la factoría. Esta podía efectuarse con diversidad de combinaciones, pero lo más frecuente fue que se tratara de un contrato temporal, sólo por un viaje de ida y vuelta. Por lo general, el compromiso se efectuaba con marinos, en especial con los responsables de las naves -maestres y pilotos-, quienes se obligaban a cuidar de los animales o a embarcar uno o varios hombres que lo hicieran por ellos (9). Muchas veces, el comerciante tenía factor en Santo Domingo; también podía realizar esta función algún conocido, paisano o amigo, así como cualquier miembro de una compañía. La retribución del factor solía consistir en un porcentaje de las ganancias (10).

En todos estos acuerdos era muy corriente que algún socio, encomendero o factor intentara apoderarse de los beneficios obtenidos o retardara excesivamente el reintegro del dinero conseguido a sus verdaderos dueños. En este sentido, fueron demasiado corrientes las quejas ante el monarca, los pleitos y los poderes notariales para saber el paradero del capital invertido y esto a pesar de que solía estipularse la duración de la unión y la obligación del socio indiano de rendir cuentas (11).

\section{IAS CONDICIONES DEL VIAJE}

Como muy bien apunta Gonzalo Fernández de Oviedo, la parte más penosa del transporte pecuario a América se encontraba en el espacio marítimo existente entre Sevilla y Canarias, en el llamado Golfo de las Yeguas, topónimo que venía a indicar las numerosas bestias que perecian en esta parte del viaje; aunque, como sigue diciendo Oviedo, también se le podía haber denominado a este trayecto marítimo Golfo de las Vacas, pues no fue menor el número de vacunos que fenecieron en dicho recorrido (12).

Las pérdidas debían ser tan frecuentes e importantes que, incluso, se generalizó la costumbre de incluir en los documentos notariales una claúsula aclaratoria que especificaba el derecho del cargador a no pagar flete o a amortizar sólo la mitad si algún animal moría antes de llegar a Canarias (13).

Respecto a los porcentajes de muertes en la travesía atlántica, parece más que evidente que no existía homogeneidad ni siquiera entre los barcos de una misma flota, pudiendo variar sustancialmente de un año a otro en función de la climatología imperante en las fechas de partida, de los tipos de ganadó embarcados y de la experiencia de los hombres encargados de su acomodo y cuidado, así como debido a las diferencias en el acondicionamiento de los buques y en su distinto tonelaje. Por los casos que conocemos, salvando algunas excepciones de extraordinaria mortandad, se pueden establecer unos porcentajes de pérdidas que oscilarían entre el $25 \%$ y el $50 \%$ de los cargamentos.

(9) APS, of. V, año 1509 , lib. único, f. 188v.

(10) APS, of. III, año 1507 , lib. $1, \mathrm{f} .117 \mathrm{v}$.

(11) APS, of. III, año 1509, lib. 1, primer tercio del legajo.

(12) Fernández de Oviedo, Gonzalo: Historia General y Natural de las Indias. Madrid, Atlas, 1954, lib. II, cap. IX, p. 37.

(13) En algunos acuerdos los compromisarios especificaban la llegada a La Gomera como fin de la claúsula que establecía el impago del flete por cualquier adversidad. APS, of. XV, año 1507, lib. único, p. $448 \mathrm{v}$. 
Muchas veces, las causas de tantos infortunios estaban en la poca comodidad de los barcos y en su escasa adaptación para tan problemáticas cargas. En otros casos, se observa que también influía la codicia de los mercaderes por aprovechar el espacio del buque contratado, porque lo habitual fue que fletaran todo el barco, la mitad o un tercio, procurando cargar las mercancias frágiles debajo de cubierta y los animales sobre ella, sufriendo éstos directamente las inclemencias del tiempo y las dificultades del viaje.

En otros casos, las naves partían sobrecargadas, porque así le interesaba al negociante. Naturalmente, con esta apreciación no queremos decir que se generalizara el hacinamiento de los ganados y su casi consecuente pérdida; existia una confortabilidad mínima, pues no son pocos los documentos de fletamento que incluyen determinadas claúsulas imponiendo a los maestres y armadores ciertos acuerdos tendentes a mejorar las condiciones del cargamento (14).

Como decíamos, no todo era despreocupación por el deseo de embarcar el máximo número de animales; mercaderes y maestres también estaban interesados en el buen suceso de la navegación. Las razones son evidentes: los primeros, tenían que pagar, cuando poco, la mitad del flete o perder una buena venta y la inversión realizada, y los segundos, veían peligrar o disminuir sus gananicias (15).

Desde los primeros años del siglo XVI, algunos de los navíos que hacían la Carrera de Indias estaban acondicionados para el transporte de cuadrúpedos, contando en su interior - después de transformar la bodega en cuadra- con almacén de grano y paja, depósitos de reserva de agua adicional, pesebreras, compartimentos separados para cada animal, así como un sistema de poleas para la carga y descarga (16).

Las medidas aplicadas para el buen suceso del viaje eran muchas más de las expuestas, pero todo ello no evitaba que un gran número de équidos y vacunos fenecieran a causa de los temporales, en cuyo caso la navegación podía ser tan peligrosa que era frecuente tirar a los animales por la borda.

En aquellos barcos no especializados, la cantidad de alimentos destinados a los mamíferos más grandes quedaban reducidos a una bota de agua, una "halda" de paja y, aproximadamente, entre siete y ocho fanegas de cebada. Si por alguna circunstancia de tormenta, temporal o calmas, la tripulación quedaba sin agua potable, antes que quedarse sin las últimas reservas, preferían tirar a los cuadrúpedos al mar o sacrificarlos. Del mismo modo, es de suponer que, mojándose la cebada o paja, la nutrición de éstos resultase muy deficiente (17).

Con el objeto de resolver las muchas emergencias que surgian a lo largo del viaje, los empresarios solian contratar a una o varias personas para que "curasen" de los ganados embarcados (18). Otras veces era el maestre quien acordaba llevar

(14) APS, of. XV, año 1507, lib. único, f. 489.

(15) En todos los contratos de fletamento se concreta esta condición, así como la fecha y puerto de salida. En muchos documentos llega a especificarse el embarque de "...todas las bestias e ganados que pueda llevar por maña y la navegación no se pueda impedir...”. APS, of. XV, año 1509 , lib. único, f. 118.

(16) APS, of. XV, año 1509, lib. único, f. 118.

(17) APS, of. $V$, año 1509 , lib. único, final del legajo.

(18) APS, of. XV, año 1507 , lib. único, f. 448v. 
a alguien en su nave para que tuviera cargo de ellos. También encontramos casos de mercaderes que viajaban en el navio; ocupándose personalmente de la correcta atención del cargamento que transportaban, adoptándose multitud de soluciones más (19).

Por último, los ganados que conseguían arribar a las costas de cualquiera de las grandes Antillas o a Ios puertos de Tierra Firme y Nueva España, llegaban tan fatigados por el largo y penoso transporte, que también debió ser alto el índice de mortandad en las nuevas tierras; en especial, porque a los animales les costaba habituarse a un cambio brusco de clima y alimentación.

No tenemos datos para calcular los porcentajes de fenecimiento en el proceso de adaptación de las partidas que llegaban a Santo Domingo, que sin duda fue el principal puerto receptor de los cargamentos, pero a tenor de algunos cálculos que hemos realizado con vacunos y ovinos trasladados desde La Española a Jamaica, y por tanto ya adaptados al trópico, dichos porcentajes debían rondar en el primer caso el 50 por cien y en el segundo entre el 50 y el 75 por cien, no en balde se precisaron cerca de cuarenta años para conseguir aclimatar algunas cabezas caprinas en La Española.

\section{LA INVERSION}

No podría entenderse la evolución del comercio pecuario entre Andalucía y América sin contar con un mínimo conocimiento de la importante inversión que debía hacerse para fletar ganados de uno a otro lado del Atlántico.

La adquisición de los animales representaba en torno al $25 \%$ de todos los gastos; en concreto, en el mercado pecuario de la Andalucía Occidental de los primeros años del siglo XVI, el precio de cada yegua rondaba los 3.500 maravedís; el valor de los caballos doblaba e, incluso, triplicaba esta cifra; cabras y ovejas -dependiendo de su edad y raza- variaban de 40 a 80 maravedis por cabeza, mientras' que cada novilla erala -vacuno menor de dos años, que era el más frecuente en los cargamentos- solía costar unos 900 maravedís.

El flete solía alcanzar el $50 \%$ de la inversión, aunque tenía importantes oscilaciones según los tipos de contratos. Por lo general el embarque de cada cabeza de ganado caballar o mular variaba de 4.500 a 6.000 maravedis, el coste del transporte de cada ejemplar vacuno estaba entre 2.000 y 2.500 maravedís, mientras que el dél ovino y caprino oscilaba entre 75 y 150 maravedís.

Un porcentaje cercano al $10 \%$ de la inversión se destinaba al acondicionamiento de las naves, cuidado y nutrición de los ganados en el viaje, mientras que el $15 \%$ o $20 \%$ restante, dependiendo de los casos, se gastaba en el establecimiento 'de seguros, abono de impuestos, alquiler de bohíos en Santo Domingo -que hacían las funciones de establos- y alimentación antes de la venta.

Los precios pagados por los ganados en Sevilla se incrementaban en La Española hasta más de diez veces, dejando unos beneficios que cotidianamente sobrepasaban el $200 \%$ de la inversión y que en algunos casos rebasaban el $1.000 \%$. En efecto, la mayor parte de los contratos de ventas de yeguas realizados

(19) APS, of. XV, año 1507, lib. único, f. 589. 
en el Santo Domingo de 1508, advierten que las cantidades abonadas por estos animales variaban de 45.000 a 135.000 maravedís, mientras que por las terneras se amortizaban cifras oscilantes entre 10.000 y 25.000 maravedís. Como es natural, estos precios fueron disminuyendo a medida que pasó el tiempo y decreció la demanda, cayendo bruscamente a principios de la década de 1510 , momento a partir del cual el comercio pecuario entre uno y otro lado del Atlántico se hizo más irregular y quedó limitado al traslado de los animales de más valor en América: mulas, garañones equinos y ovinos y algunas remesas caprinas.

El elevado valor que adquirían los ganados en las Antillas venía determinado por una larga lista de factores entre los que cabe citar el coste del flete, los altos tipos de interes cobrados por las ventas fiadas que se hacian en La Española o por las compras realizadas en Andalucía con letras de cambio pagaderas en Sevilla al retorno de Santo Domingo, los siempre elevados riesgos, el coste de los seguros y la ganancia del mercader (20).

Sin ninguna duda, estas particularidades comerciales infiúan en la elevación de los gastos, pero no vamos a entrar en su estudio, porque sería desviarnos del tema central que nos ocupa (21).

\section{LAS RAZONES DE LA DEMANDA GANADERA}

Un mero análisis de la periodización que establecimos en páginas atrás para el comercio atlántico de ganados evidencia que -sin tener en cuenta los esporádicos cargamentos que llevaron las primeras armadas- la regularización de este tráfico comenzó en una fecha tardía (1504), doce años después del descubrimiento. Las razones que explican este retardado progreso del comercio ganadero son varias y su justificación es un tanto compleja y amplia, por lo que vamos a tratar de sintetizarla seguidamente.

En la primera isla colonizada, La Española, parece evidente que los pobladores asentados en ella no se aventuraron antes a adquirir ganados, porque casi todos ellos querían obtener beneficios rápidos -con los que volver a España- sin hacer demasiadas inversiones en sectores que les atasen a la tierra y porque, en este último supuesto, necesitaban gastar importante sumas, que naturalmente tardaban en ahorrarse. Por añadido, hay que tener presente que el negocio de la cría vacuna, ovina o caprina no ofrecía un beneficio seguro, dada la abundancia y baratura del porcino, único sector pecuario que tuvo un importante desarrollo durante los últimos años del siglo XV y los primeros del siglo XVI.

Este contexto cambió con la crisis de la minería y el retroceso de la población aborigen, fenómenos que comenzaron a evidenciarse a principios de 1507 . Por esta fecha, los hombres más ricos, aquellos que tenían ya intereses económicos lo suficientemente importantes como para permanecer o establecerse en la

(20) Mercado, Tomás de: La economía en la Andalucía del descubrimiento. Sevilla, Edit. Andaluzas, 1985, p. 102.

(21) Para el estudio de estas temáticas, referidas al comercio del XVI, véanse los trabajos de Pierre y Huguette Chaunu (Seville et l'Atlantique. Paris, SEUPEN, 1955-1960) y de Eufemio Lorenzo Sanz: Comercio de España con América en la época de Felipe II. Valladolid, SeverCuesta, 1979-1980, ts. I y II. 
isla, se vieron obligados a buscar nuevas alternativas económicas. Estas nuevas posibilidades se creyeron encontrar en la ganadería, tal y como se comprueba en las propuestas que presentaron en Burgos los representantes isleños en la primavera de este mismo año- a Fernando el Católico.

Desde un punto de vista del abasto, parece que la decisión anterior estuvo también motivada por la escasez de carne porcina -muy importante en la alimentación de españoles e indios- que siguió a la pérdida de buena parte de las piaras existentes en La Española con los ciclones de 1508 y 1509. Esta carencia y la problemática que entrañaba la crianza porcina en las riberas de los caudalosos ríos dominicanos, debíó ser determinante en la gestación y generalización del deseo, entre autoridades y colonos, de diversificar tanto la producción como el proveimiento cárnico.

Por último, desde la perspectiva de los precios, parece evidente que el cambio coyuntural que provocaron los huracanes anteriormente citados -se pasó de la abundancia a la casi absoluta carencia de carne-, fue determinante en el brusco aumento de los precios, circunstancia que explica el que la compraventa de ovinos y vacunos se convirtiera en un boyante negocio; mientras que, por otra parte, este interés económico justifica el repentino deseo de muchos vecinos y mercaderes de importar ganados de Andalucía y Canarias (22).

Del mismo modo, en España también existieron circunstancias adversas que imposibilitaron el desarrollo del comercio ganadero. Hasta 1504 la población sevillana -mercaderes y vecinos relacionados con el comercio- no intervino en el transporte pecuario, porque todas las actividades económicas relacionadas con América estaban monopolizadas por la Corona; en fechas posteriores, hasta el repentino comienzo en 1507 de las exportaciones de ovinos, caprinos y vacunos, el tráfico se restringió también por la interacción de varias razones, entre las que cabe citar la imperiosa necesidad que tenían los colonos de importar caballos para asegurar el sometimiento militar de la población aborigen y los cuantiosos gastos que se hicieron en tales compras, circunstancia que imposibilitó a los más ricos invertir en otros ramos pecuarios e incentivó a los mercaderes a cargar sólo los animales con más demanda y precio.

Del mismo modo, también debieron influir en el retraso del comercio pecuario las malas cosechas que hubo durante estos años en toda la Andalucía Occidental y las paralelas crisis de subsistencia que padeció el reino de Sevilla, coyuntura que dificultó el tráfico, debido al encarecimiento de las carnes y a las medidas políticas que arbitraron algunos Concejos; prohibiendo la exportación de ganados desde sus términos, por temor a los efectos del hambre, tal y como hicieron Sevilla y algunas ciudades canarias.

En resumen, durante los primeros años de colonización, la ausencia de importantes capitales en manos de la población con interés en la colonización y la mayor atracción que ejercieron los équidos, orientaron la inversión hacia este tipo de ganados hasta que los españoles no estuvieron preocupados por conseguir mayores y más variadas 'cantidades de carne, tuvieron necesidad de ello, se

(22) Rodríguez Demorizi, Emilio: El pleito Ovando-Tapia. Comienzos de la vida urbana en América. Santo Domingo, Edit. del Caribe, 1978, pp 238-286. 
sintieron motivados e incentivados para permanecer en la tierra o creyeron que tal actividad proporcionaría ganancias sustanciales.

\section{LOS MERCADOS Y LAS FASES COMERCIALES REGIONALES}

El nuevo rumbo que en adelante seguiría la joven ganadería americana vino determinado por la evolución del mercado interno de la primera isla que tuvo un importante desarrollo pecuario: La Española. El análisis de este caso es importante porque nos proporciona las pautas de comportamiento de los ganaderos en las restantes Antillas y, al mismo tiempo, nos ofrece el primer -y principal- punto de referencia en el estudio del mercado regional.

A principios de la década de 1510 , con la recesión definitiva en la minería -fenómeno que se repitió en todas las islas del Caribe, dado el carácter cíclico de la extracción aurífera- y el creciente progreso de la producción pecuaria, la cría de ganados entró también en crisis ante la drástica reducción de la demanda y la paralela disminución de los precios. Apareció pues una dinámica que, a medida que transcurrió el tiempo, fue generalizándose en el resto de las Antillas y en los territorios que se habían colonizado en Nueva España, Tierra Firme y Perú: la búsqueda de expectativas exteriores que generasen nuevos mercados.

Atendiendo a la evolución de los precios en el primer mercado de América, se puede observar que en Santo Domingo la estimación del arrelde de ternera pasó de algo más de 50 maravedís a principios de la década de 1510 a 6 maravedís en 1520 y a sólo 2 ó 3 maravedís en 1528. La evolución de los precios de los restantes ramos ganaderos fue semejante, siendo la regresión mucho mayor en el caso de los équidos, cuyas pieles y carnes no se comercializaban. A lo largo de las décadas de 1510 y 1520 la disminución del valor del ganado -0 de sus productos- en Puerto Rico, Jamaica y Cuba fue muy semejante al caso dominicano y lo mismo ocurrió en Nueva España, Tierra Firme y Perú en posteriores etapas.

Durante la primera mitad del siglo XVI, los ganaderos siempre trataron de remediar el decrecimiento de las ganancias en los mercados locales -situación a la que se llegaba irremisiblemente en menos de una década de colonizaciónbuscando otras alternativas en el ámbito europeo o en el regional; en este último caso, a través de la expansión militar, ampliando el poblamiento a puntos geográficos más distantes y con mayores posibilidades económicas, ya fuera porque dispusieran de metales o porque contaran con una importante población autóctona para emplearla como medio de producción o como medio de cambio.

Así pués, sintetizando, las alternativas ideadas en el siglo XVI para paliar las crisis de los mercados locales, fueron tres, sucediéndose de forma paralela en el tiempo:

La primera opción que se desarrolló estuvo en la potenciación y abasto a expediciones de razzias y huestes de conquista que se constituían y financiaban en las propias Antillas, así como en el aprovisionamiento de las flotas de colonización que se dirigían al continente o a las naves que regresaban a España.

La segunda alternativa ideada consistió en el desarrollo de las exportaciones hacia las fundaciones poblacionales que se iban creando o hacia los reales mineros que se descubrían, así como hacia algunos centros redistribuidores de ganados, desde donde partían o se abastecian nuevas huestes o focos de colonización. Como el principal medio de cambio eran los esclavos indios, cuando finalizaba la 
conquista y se encomendaba la población era forzoso iniciar la búsqueda de minas en aquellas tierras ya colonizadas, donde no era posible emprender nuevas conquistas, tratando de encontrar otras expectativas económicas para mantener el intercambio con Europa y financiar las demandas agropecuarias internas.

Por último, la tercera alternativa buscaba la exportación a Sevilla de productos con demanda en Europa, esencialmente cueros y sebo.

Pese a la importancia del comercio con Sevilla, dada la creciente disminución del consumo local de carnes y la pérdida del control de la exportación y distribución de los cueros en: Europa, que cayó en manos de mercaderes sevillanos, ya a principios de la década de 1520 el mercado más importante de La Española, y antillano por extensión, estuvo en el ámbito regional, desarrollándose en cuatro etapas (23).

Las fases del comerio regional se relacionaban con la aparición de nuevas demandas en los distintos puntos geográficos objeto de conquista o colonización. El criterio que hemos establecido para su periodización atiende al origen de la retaguardia proveedora y al destino de los cargamentos en la vanguardia conquistadora.

Según estos planteamientos, se puede hablar de una fase antillana, que se extendió desde fines de la primera década del siglo XVI hasta principios del decenio de 1520; de una segunda etapa novohispana-centroamericana, que se desarrolló entre principios de esta última década y mediados de los años 1530; de una tercera corriente que podemos denominar de Tierra Firme, que comenzó a principios de la década de 1530 y acabó poco después de conocerse la promulgación de las Leyes Nuevas de 1542 y de un cuarto período peruano-colombiano cuyos principios podemos establecer a mediados del decenio de 1530 , y su final, al término de la década de 1560, aunque con dos interfases antes y después de 1542:

Cada una de estas etapas se desarrollaba en dos interfases distintas: durante los primeros años las exportaciones se limitaban casi exclusivamente a caballos y puercos -o tocinos en su defecto- para el abasto de las huestes, mientras que una vez que acababa la conquista y avanzaba: el proceso de colonización predominaban en el comercio ovinos y vacunos, seguidos de équidos y caprinos.

En la primera etapa del comercio regional ganadero, los principales criadores de ganados de La Española -apoyados por los miembros de la Administración dominicana, que también eran ganaderos- convirtieron a la isla en un centro exportador de productos agropecuarios, predominando ya esta actividad más que la minera (24).

A lo largo de dicho período la venta de caballos -también de puercos, tocinos y tasajos-, en un primer momento, y de 'ovinos y vacunos, en cuanto llegó la colonización a las Antillas y el foco del Darién, constituyó el pilar principal de la economía de La Española. Por entonces, la mera constitución de una hueste elevaba los precios de los productos ganaderos, revitalizaba las expectativas de

(23) 'Carta respuesta a los oidores, 14-IX-1526. AGI, Indiferente General, 421, lib. 11, f. 179.

(24) En 1505 Vicente Yáñez Pinzón y los que iban con él a poblar Puerto Rico recibían' licencia para sacar de La. Española mantenimientos "y otras cosas" sin pagar derechos. AGI, Indiferente General, 418 , lib. 3, p. $163 \mathrm{v}$. 
negocio y proporcionaba una alternativa económica a los focos poblacionales de economía ganadera, sólo con la simple esperanza de percibir los medios de cambios -metales y esclavos- con que la vanguardia pagaba sus adquisiciones.

El segundo periodo del comercio interregional (desde principios de la década de 1520 hasta mediados de la de 1530) se caracterizó por un notable incremento numérico y geográfico de los mercados -Nueva España, Guatemala, Honduras, Nicaragua y Panamá-, por el desarrollo de la cría caballar en las grandes Antillas y por la competencia entre los principales productores isleños.

La tercera etapa (desde principíos de la década de 1530 hasta 1542) puede definirse por la continuación de los mercados del periodo anterior -pero en su segunda interfase-, por la aparición de otros centros demandantes en Tierra Firme -Venezuela, Cartagena de Indias, Santa Marta, Nombre de Dios y Panamá, sustantialmente- y por la creación de una fuerte demanda en Perú; mientras tanto, asistimos a un paralelo incremento de la competencia entre los productores, desapareciendo los antiguos importadores de la década anterior (Nueva España, Nicaragua y Guatemala), que pasaron a incrementar el número de exportadores y a competir con las Antillas. Este tercera fase del comercio ganadero regional fue truncada por la promulgación de las Leyes Nuevas en 1542, legislación que supuso la ruptura de gran parte del sistema de valores establecido durante la conquista, desequilibrando la estabilidad de instituciones como la encomienda o la esclavitud india y arruinando a los centros proveedores antillanos.

La cuarta y última fase interregional se centró en el Perú y el Nuevo Reino de Granada, con importantes demandas entre 1536 y 1543, que eran atendidas desde las Antillas, Panamá y los puertos de la vertiente pacífica de Nicaragua y Nueva España. Tras un período de crecimiento del comercio en el que predominó el ganado caballar -entre mediados y finales de la década de 1530- para atender las necesidades de pizarristas y almagristas durante las Guerras Civiles, asistimos a un relanzamiento de las exportaciones equinas como consecuencia del conflicto entre realistas y pizarristas después de la aplicación de las Leyes Nuevas. Transcurridos estos años de guerras, el tráfico de otras especies de ganados creció paulatinamente hasta fines de la década de 1550 , llegando ya mayoritariamente desde Quito y la meseta de Bogotá, declinando a lo largo de todo el decenio de 1560 .

\section{LOS EMPRESARIOS-GANADEROS}

Desde principios de la década de 1510 la participación antillana en el proveimiento pecuario tuvo una doble vertiente. Por un lado, nos encontramos con un conjunto de puertos, a la cabeza de los cuales estaba Santo Domingo, donde arribaban las huestes para avituallarse de alimentos y pertrecharse de caballos y armas. En cada uno de estos puertos existía un nutrido grupo de empresarios que, una vez partidos los expedicionarios, se profesionalizaban en su abastecimiento.

Por otro lado, las Antillas también fueron importantes centros organizadores de armadas, entradas o razzias, huestes de conquista y expediciones de colonización. Sin duda, en este segundo papel también destacó el puerto de Santo Domingo y la propia isla Española, constituyéndose en ella numerosos contingentes de conquistadores con sus propios hombres y capitales. 
Las intervenciones de los ganaderos en el negocio de la conquista tenía muy distintas facetas; unas veces actuaban como financieros y prestamistas -más frecuentemente a través de la cesión fiada de animales y alimentos que de acopios monetarios- y otras como proveedores directos o indirectos (en este último caso, cuando vendían sus potros y reses a los mercaderes que intervenían en el comercio con el continente o compraban los aherrojados que éstos llevaban a las islas) $\mathrm{e}$, incluso, como capitanes de hueste.

Algunas veces, esta participación era puramente fortuita, pero no son pocas las empresas emprendidas conscientemente, buscando el negocio de la comercialización pecuaria mediante la venta de caballos, tocinos y tasajos; en otros casos, cuando la intervención no fue directa, es indiscutible que las expediciones sirvieron para comercializar sus producciones (25).

El grupo dirigente de La Española estaba constituido por los ganaderos más importantes de la isla, esto es, por los miembros de la propia Administración insular, por aquellos que años después serían los señores de ingenio más destacados, los capitanes de buena parte de las huestes que operaron en el continente y los gobernadores de distintos territorios caribeños. Nos referimos a nombres tan conocidos como Diego Colón, el contador Gil González Dávila, el factor Juan de Ampiés, el tesorero Miguel de Pasamonte, los jueces Ayllón, Matienzo y Villalobos y una veintena de cabildantes y vecinos principales.

Entre estos últimos, en Santo Domingo destacaban Juan Mosquera, el licenciado Serrano, Francisco Tostado, el bachiller Velosa, Gonzalo de Guzmán, Fernando Caballero, el antiguo tesorero Santa Clara, Jacome Castellón, Lope de Bardecí, Francisco de Garay, García de Lerma, Rodrigo de Bastidas, Diego López de Salcedo y Jerónimo de Grimaldo. A este grupo se sumaban en Concepción de la Vega Pedro de Murcia y algunos otros vecinos; en Santiago el licenciado Becerra, Rodrigo Chamorro y Pedro de Herrera; en Higüey Ponce de León y los hermanos Trejo; en Salvatierra de la Sabana Francisco Velázquez; y. finalmente, en Puerto Plata, Francisco de Ceballos, Francisco de Barrionuevo y Fernando de Jaen (26).

Después de 1520 a este grupo de dominicanos se unieron las élites puertorriqueña, jamaicana y cubana, empresarios que en realidad procedian de la bifurcación del grupo dirigente de La Española.

Los personajes más poderosos de las islas fueron los que, en contínuas y permanentes expediciones, crearon constantes vanguardias, operando en las zonas de frontera ocupadas por el indio infiel y formando ellos mismos y sus compañeros de intereses la retaguardia proveedora (27).

\section{LOS MEDIOS DE CAMBIO EN EL COMERCIO REGIONAL}

Los inversores que planearon y constituyeron tan múltiples expediciones, buscaban ganancias y éstas se manifestaban a través de la consecución de los dos

(25) Carta del licenciado Zuazo, 22-I-1518. Colección de Documentos Inéditos de América y Oceanía. Madrid, Imprenta de Manuel G. Hernández, 1864-1889, t. XXXIV, p. 251.

(26) Ibid., p. 227.

(27) Carta de los Jerónimos, 10-I-1519. Moya Pons, Frank: La Española en el siglo XVI, 14931520. República Dominicana, Santiago, Universidad Católica Madre y Maestra, 1971, p. 241. 
únicos medios de cambio -en la América de este período no existía una importante circulación monetaria- que podían amortizar sus gastos: oro y esclavos.

El botín o los vencidos eran siempre imprescindibles para sufragar los cuantiosos préstamos que recibían los miembros de las huestes y los vecinos de las primeras fundaciones poblacionales, así como para adquirir los pertrechos y ganados necesarios para el establecimiento colonial. Los españoles buscaban el oro desesperadamente, para pagar deudas y ganar una posición económica y social, pero fueron pocas las ocasiones y regiones donde se encontraron tesoros importantes -si exceptuamos los casos de México, Bogotá y Cajamarca- y aún en estas ocasiones los dividendos obtenidos resultaban insuficientes para muchos soldados.

Así pues, en casi toda América, hubo de recurrirse a la esclavización de los nativos a través de múltiples fórmulas. Dada la polémica que levantó el Requerimiento, empleado por primera vez por Pedrarias Dávila en Panamá a lo largo de 1514, y los posteriores debates que mantuvo Las Casas con Sepúlveda, lo más frecuente fue aplicar algunos conceptos tradicionales del derecho de guerra como el casus belli, precepto existente en el derecho medieval castellano para justificar la guerra, mediante el cual se legitimaba la esclavización de todos aquellos que eran derrotados en justa batalla o de aquellos otros que habiéndose sometido a la Corona se levantaban en rebeldía. Al respecto, conviene precisar que, con más frecuencia de la que se ha creido, ante las fuertes deudas y los apremios de los acreedores, los conquistadores recurrieron a la provocación o a la invención del levantamiento de los indios para justificar y legalizar su esclavización.

Metales y esclavos eran reciclados en los puertos antillanos para ser reinvertidos en nuevas expediciones, en distintos negocios agropecuarios -especialmente en los ingenios de azúcar, demandantes constantes de abundante mano de obrao para sufragar el déficit que el comercio isleño mantenía con Sevilla, constituyendo esta interconexión entre el continente, las Antillas y Sevilla el fundamento de la economía caribeña durante las cuatro primeras décadas del siglo XVI.

Fenecidas las conquistas, ante la limitación de la demanda europea de cueros y la progresiva reducción de sus precios en Sevilla, los únicos mercados duraderos estuvieron en las ciudades administrativas o comerciales (México, Veracruz, Cartagena de Indias, Panamá o Lima) y en los reales mineros, especialmente en Zacatecas y Potosí. La existencia de estos dos polos económicos es la que explica las progresiones pecuarias del norte mexicano y del centro-sur del virreinato peruano, es decir de gran parte de las poblaciones del Collao y Charcas. Naturalmente, los reales mineros eran muchos más; en Nueva Galicia, Nueva Vizcaya y Nuevo México también jugaron un importante papel las minas de Durango, Salti1lo, Fresnillo y El Parral, entre otras muchas. De la misma manera, en el Perú también generaron una gran demanda otros centros productores de mercurio y plata, como Huancavélica y Castrovirreina, respectivamente, por citar sólo los más conocidos.

Esta relación entre ganadería y minería que se desarrolla durante la segunda mitad del siglo XVI, no es tan evidente en la primera mitad de la centuria, período durante el cual el comercio ganadero tuvo muy diversos intervalos en cada una de las regiones americanas, debido a la heterogeneidad geográfica y climática de los territorios donde operaban las huestes, a la evolución cronológica del proceso de conquista, a la periodicidad que existió en la extracción de metales y a la disparidad de cada región en riqueza minera y poblacional. 